\title{
Internet Usage Pattern of Adolescents
}

\author{
B.Prashanthi M.Sc., \\ Department of Human Development and Family studies, College of Home science, Professor Jayashankar State \\ Telangana Agriculture University
}

\begin{abstract}
ABSRACT:- The internet usage by adolescents was studied using a questionnaire. Sample consisted of students from different professional and non professional courses. The study revealed that the adolescents were using internet in medium range. And majority of the sample was using mobile phone to access internet. Students said that they prefer spending much more time online at home compared to college. Adolescents were having accounts in atleast two social networking websites
\end{abstract}

\section{INTRODUCTION}

The Internet is a global system of interconnected computer networks that use the standard Internet protocol suite (TCP/IP) to serve billions of users worldwide. It is a network of networks that consists of millions of private, public, academic, business and government networks of local to global scope that are linked by a broad array of electronic, wireless and optical networking technologies. The Internet carries a vast range of information resources and services such as the inter-linked hypertext documents of the World Wide Web (WWW) and the infrastructure to support email. In recent years the Internet has become a central arena of activity for children and youth for information needs, interpersonal communication, entertainment needs and social needs. Through the Internet they listen to music, play games, seek information, talk with their friends, write about themselves, show their pictures, meet new people, respond to what others have said and much more.In other words, the virtual world has become an integral part of the physical world of children and adolescents. Accordingly, the amount of time they spend in front of the computer screen is increasing.The Internet is becoming increasingly influential for many people. It seems that there is no aspect of life that use the Internet does not touch (Erdogan, 2008). For many adolescents the Internet is the main source of information and entertainment, and is an important tool for communication (Lenhart, Madden and Hitlin, 2005; Mesch and Talmud, 2006; Livingstone and Helsper, 2007). They reportedly prefer being online to other media, including the telephone, TV, and radio (Louge, 2006).

OBJECTIVE: To study the internet usage by adolescents

\section{MATERIALS \&METHODS}

Exploratory research design was used for the present study. The study was carried out in Hyderabad city.

Selection of sample:

- Purposive sampling procedure was used to select sample for the present study.

- Sample comprised of 200 adolescents with equal number of boys and girls

Sampling procedure: Criteria for sample selection are:

1. Age range of adolescents should be between 18-22 years

2. Students doing graduation from professional and non-professional colleges.

MEASUREMENT TOOL A Questionnaire was developed for the study which includes the general information of respondents. Questionnaire covers questions on pattern of use of internet in a day The data was analyzed using frequencies, percentages.

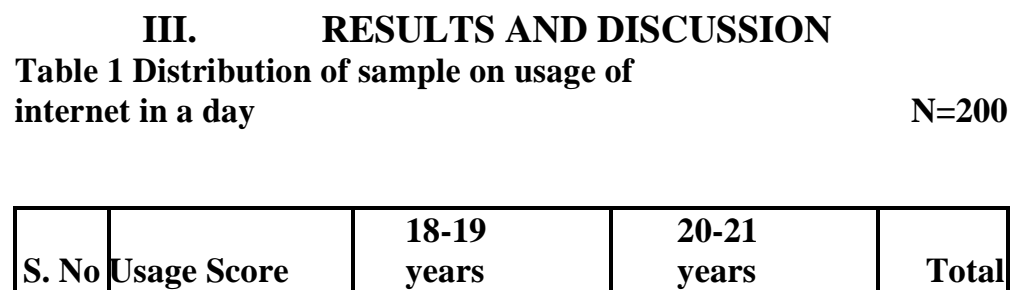




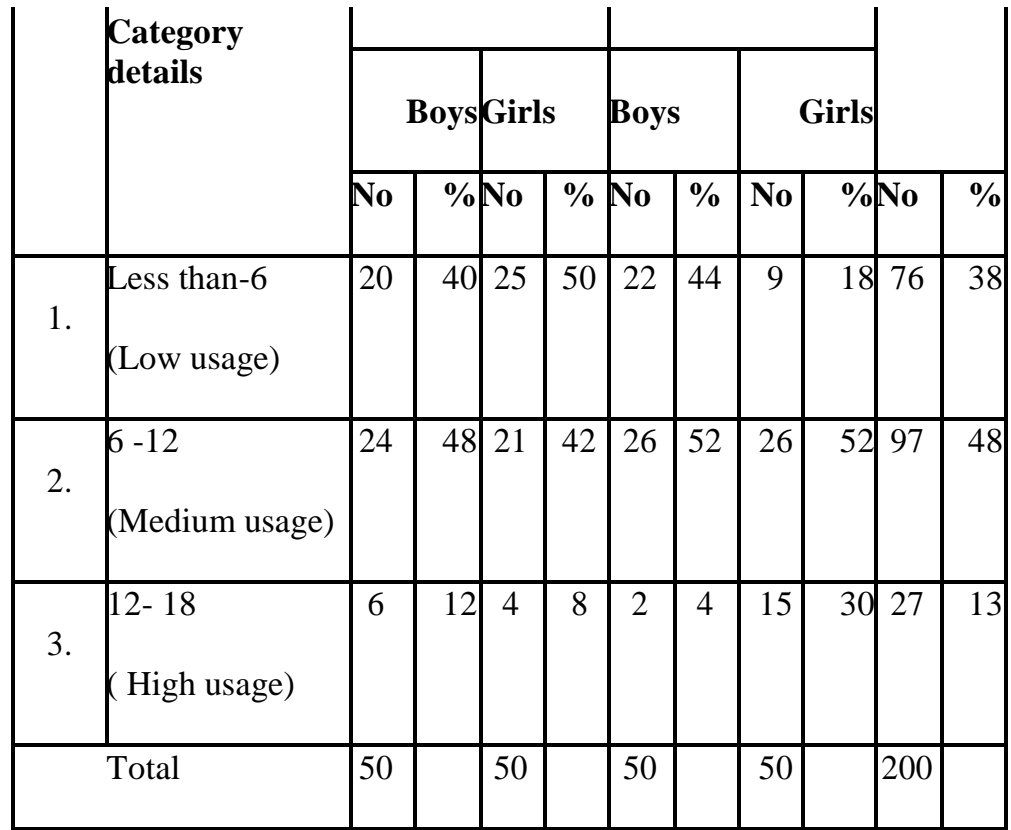

From the above table it is clearly indicated that the higher percent $(48 \%)$ of boys under the age group of 18-19 years rated that they are medium users of the internet and 40 percent girls also fell in the low usage range. Few numbers of boys and girls were found to be high users of internet. This trend was changed in the age group of 20-21 years. Same percent (52\%) of boys and girls were found in the medium usage group. Around 44 percent of boys of 20-21 years were found to be low users. The overall percent of both boys and girls in both the age groups rated that 48 percent are medium internet users and 38 percent are low internet users. The reasons for the medium usage of internet might be because they cannot use internet for chatting,collecting information, entertainment and other activities daily. They use it only sometimes as and when they need.

Table 2Distribution of sample on source of internet connection $\quad \mathrm{N}=\mathbf{2 0 0}$

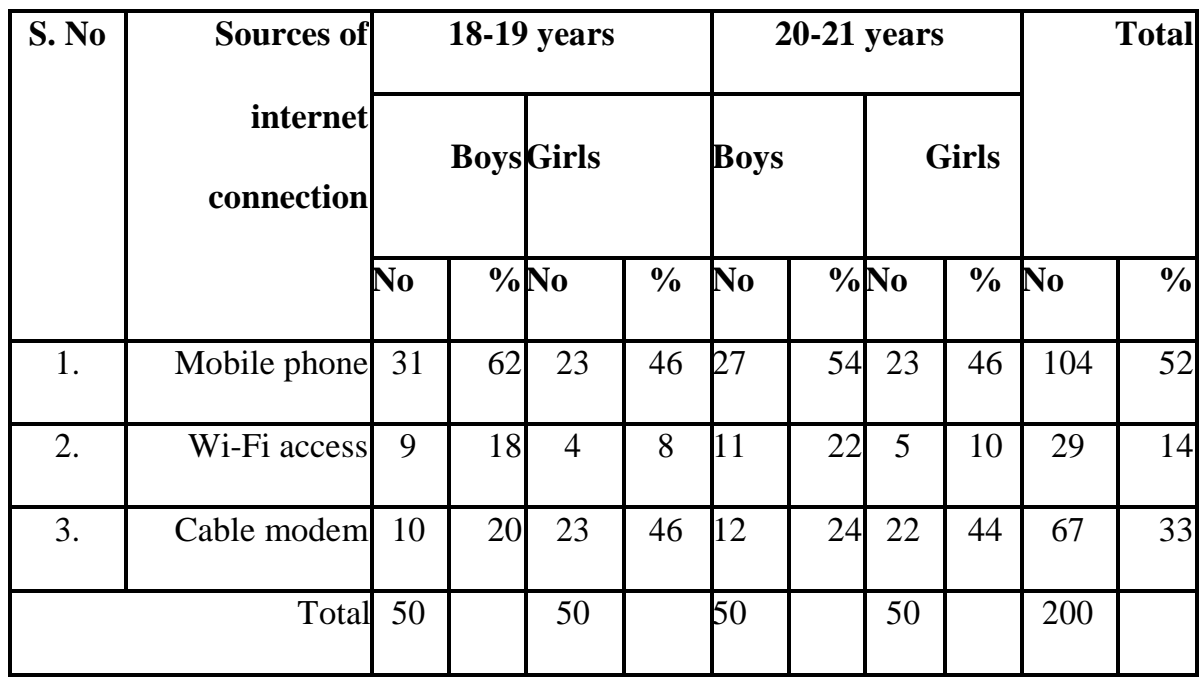

From the above table the results reveal that 62 percent of boys under 18-19 years age group stated that they use mobile phones to access the internet. But girls in the same age group (46\%) preferred to access internet through both mobile phones and cable modem. In the age group of 20-21 years, both boys and girls mentioned that they use mobile phone for connecting internet. When the total sample is considered, this table indicates that one third sample $(33 \%)$ is accessing internet through cable modem. The major result drawn is that half of the sample is using mobile phone to access internet. Highest percent of sample had shown interest in using internet through mobile phone because mobile phones can be easily operated, easy to handle and also it can be used whenever and wherever needed. 
Table 3. Distribution of sample on use of number of social networking websites $\mathbf{N}=\mathbf{2 0 0}$

\begin{tabular}{|c|c|c|c|c|c|c|c|c|c|c|c|}
\hline \multirow[t]{3}{*}{ S. No } & \multirow{3}{*}{$\begin{array}{c}\text { Number of } \\
\text { social } \\
\text { networking web } \\
\text { sites }\end{array}$} & \multicolumn{4}{|c|}{ 18-19 years } & \multicolumn{4}{|c|}{ 20-21 years } & \multicolumn{2}{|c|}{ Total } \\
\hline & & \multicolumn{2}{|r|}{ Boys } & \multicolumn{2}{|c|}{ Girls } & \multicolumn{4}{|c|}{ Boys Girls } & \multirow[b]{2}{*}{ No } & \multirow[b]{2}{*}{$\%$} \\
\hline & & No & $\%$ & No & $\%$ & No & $\%$ & No & $\%$ & & \\
\hline 1. & One & 15 & 30 & 18 & 36 & 11 & 22 & 17 & 34 & 61 & 30 \\
\hline 2. & Two & 17 & 34 & 25 & 50 & 18 & 36 & 21 & 42 & 81 & 40 \\
\hline 3. & Three & 9 & 18 & 5 & 10 & 14 & 28 & 9 & 18 & 37 & 18 \\
\hline 4. & Four & 9 & 18 & 2 & 4 & 7 & 14 & 3 & 6 & 21 & 10 \\
\hline & Total & 50 & & 50 & & 50 & & 50 & & 200 & \\
\hline
\end{tabular}

From the above table the results revealed that, forty percent of students have accounts in two social networking websites. Thirty percent of the students have one social networking account and another eighteen percent have three accounts, where more boys ( 28 percent) of higher age group got three accounts. The reasons for three accounts might be because they are involved in using number of social networking websites for entertainment, chatting, music downloads and information gathering.Many of the adolescents have more than two social networking websites like Facebook, twitter, Orkut etc. The reasons could be that they use different websites for their enjoyment, to maintain relationships as well as communicating with others and making new friends.

Table 4. Distribution of sample on purpose of using internet

$\mathbf{N}=\mathbf{2 0 0}$

\begin{tabular}{|c|c|c|c|c|c|c|c|c|c|c|c|}
\hline \multirow[t]{3}{*}{ S. No } & \multirow{3}{*}{$\begin{array}{l}\text { Purpose of using } \\
\text { internet }\end{array}$} & \multicolumn{4}{|c|}{ 18-19 years } & \multicolumn{4}{|c|}{ 20-21 years } & \multirow{2}{*}{\multicolumn{2}{|c|}{ Total }} \\
\hline & & \multicolumn{2}{|c|}{ Boys } & \multicolumn{2}{|c|}{ Girls } & \multicolumn{2}{|c|}{ Boys } & \multicolumn{2}{|c|}{ Girls } & & \\
\hline & & No & $\%$ & No & $\%$ & No & $\%$ & No & $\%$ & No & $\%$ \\
\hline 1. & $\begin{array}{l}\text { Information } \\
\text { Gathering }\end{array}$ & 10 & 20 & 22 & 44 & 15 & 30 & 27 & 54 & 74 & 37 \\
\hline 2. & Games & 18 & 36 & 8 & 16 & 7 & 14 & 8 & 16 & 41 & 20 \\
\hline 3. & Movies & 7 & 14 & 2 & 4 & 8 & 16 & 6 & 12 & 23 & 11 \\
\hline 4. & T.V Shows & 4 & 8 & 1 & 2 & 0 & 0 & 2 & 4 & 7 & 3 \\
\hline 5 & Music Albums & 11 & 22 & 17 & 34 & 16 & 32 & 7 & 14 & 51 & 25 \\
\hline 6. & $\begin{array}{l}\text { Any other } \\
\text { (Video chatting) }\end{array}$ & 0 & 0 & 0 & 0 & 4 & 8 & 0 & 0 & 4 & 2 \\
\hline & Total & 50 & & 50 & & 50 & & 50 & & 200 & \\
\hline
\end{tabular}


The above table clearly indicated that in 18-19 years age group, 36 percent of boys mentioned that they use internet only for games. Nearly 44 percent girls of same age group mentioned that they use internet for information gathering. In the 20-21 years age group, 32 percent of boys mentioned that they use internet for music albums. Fifty four percent of girls mentioned that they use internet for information gathering. Thirty seven percent of total sample use internet only for information gathering because half of the girls irrespective of the age were using internet only for information gathering. Another 25 percent of them use internet for down loading music albums. Purpose of using internet by most of the adolescents for gathering information might be because they are pursuing their studies and also to improve their knowledge and to know the news that happens in the surroundings. The other reasons for using the internet could be for music albums for their enjoyment purpose.

Table 5 Distribution of sample on type of websites used

\begin{tabular}{|c|c|c|c|c|c|c|c|c|c|c|c|}
\hline \multirow[t]{3}{*}{ S. No } & \multirow{3}{*}{$\begin{array}{c}\text { Type of } \\
\text { websites } \\
\text { Used }\end{array}$} & \multicolumn{4}{|c|}{ 18-19 years } & \multicolumn{4}{|c|}{ 20-21 years } & \multicolumn{2}{|l|}{ Total } \\
\hline & & \multicolumn{4}{|c|}{ Boys Girls } & \multicolumn{2}{|c|}{ Boys } & \multicolumn{2}{|c|}{ Girls } & & \\
\hline & & No & $\%$ & No & $\%$ & No & $\%$ & No & $\%$ & No & $\%$ \\
\hline 1. & Google & 13 & 26 & 23 & 46 & 17 & 34 & 13 & 26 & 66 & 33 \\
\hline 2. & Face book & 32 & 64 & 25 & 50 & 28 & 56 & 35 & 70 & 120 & 60 \\
\hline 3. & Twitter & 5 & 10 & 2 & 4 & 5 & 10 & $\overline{2}$ & 4 & $\overline{14}$ & 7 \\
\hline & Total & 50 & & 50 & & 50 & & 50 & & 200 & \\
\hline
\end{tabular}

From the above table the results revealed that, sixty percent of total sample mentioned that they use ace book and 33 percent of the students reported that they use Google. Very few (7\%) students are using twitter. This shows that face book is very popular among graduate college students irrespective of the gender and age group.The reasons for using face book might be this site is an accepted means of communication and also it is a never ending virtual social gathering filled with adopted people and also to make friends with unknown persons and also due to various networks.A study conducted on number of social networking sites (Boyd and Ellison, 2007) also revealed that moreover, the Internet enables one to send the same message to many friends or to all the members of an organization and provides greater ability to manage her social network through social platforms such as face book.

Table 6 Distribution of sample on time spent on internet

\begin{tabular}{|c|c|c|c|c|c|c|c|c|c|c|c|}
\hline \multirow[t]{3}{*}{ S. No } & \multirow{3}{*}{$\begin{array}{l}\text { Time spent on } \\
\text { internet in a day }\end{array}$} & \multicolumn{4}{|c|}{ 18-19 years } & \multicolumn{4}{|c|}{ 20-21 years } & & \multirow[t]{2}{*}{ Tota } \\
\hline & & \multicolumn{2}{|c|}{ Boys } & \multicolumn{2}{|c|}{ Girls } & \multicolumn{4}{|c|}{ Boys Girls } & & \\
\hline & & No & $\%$ & No & $\%$ & No & $\%$ & No & $\%$ & No & $\%$ \\
\hline 1. & Few minutes & 17 & 34 & 13 & 26 & 13 & 26 & 13 & 26 & 56 & 28 \\
\hline 2. & Less than 1 hour & 8 & 16 & 11 & 22 & 13 & 26 & 11 & 22 & 43 & 21 \\
\hline 3. & 1 to 2 hours & 18 & 36 & 21 & 42 & 16 & 32 & 24 & 48 & 79 & 40 \\
\hline
\end{tabular}




\begin{tabular}{|l|l|l|l|l|l|l|l|l|l|l|l|} 
4. $\quad$ More than 2 hours & 7 & 14 & 5 & 10 & 8 & 16 & 2 & 4 & 22 & 11 \\
\hline Total & 50 & & 50 & & 50 & & 50 & & 200 & \\
\hline
\end{tabular}

From the above table, the results revealed that 40 percent of boys and girls of both the age groups mentioned that they spend 1 to 2 hours of their time on internet. Very less percent (11 percent) sample spend more than 2 hours a day and boys seem to be spending more time on internet than girls in both the age groups. The reasons for the adolescents to spend 1 to 2 hours on internet than watching TV could be because of abundance of media choice on the internet. Internet as a means for socialization, education, information access, entertainment, shopping and communication is increasing dramatically. Ellery (2008) studied the usage of internet by adolescents and found that the younger generation views the internet as a useful source of information and channel for speedy communication. It is also an effective medium of socialization

\section{CONCLUSION}

The study concludes that the adolescents were using internet in medium range. And majority of the ample was using mobile phone to access internet. Students said that they prefer spending much more time online at home compared to college. Adolescents were having accounts in atleast two social networking websites. Most of the respondents used internet only for information gathering. Majority of the sample used face book and 33 percent of the students reported that they use Google and very few (7\%) students were using twitter. They spend 1 to 2 hours of their time on internet. Face book was very popular among graduate college students irrespective of the gender and age group.

\section{REFERENCES}

[1] Boyd, d., \& Ellison, N. (2007). Social network sites: Definition, history, and scholarship. Journal of ComputerMediated Communication 13, 210-230.

[2] Erdoğan, Y. (2008). Exploring the Relationships among Internet Usage, Internet Attitudes and Loneliness of Turkish Adolescents. Cyberpsychology: Journal of Psychosocial Research on Cyberspace, 2(2), article 1.

[3] Lenhart, A., Madden, M and Hitlin, P. 2005. Teens and technology: you are leading the transition to a fully wired and mobile nation. fromwww.pew Internet.org.

[4] Mesch, G. S. 2003. The family and the internet: The Israeli case. Social science Quarterly, 84, 1039 1050 .

[5] Livingstone and Helsper, 2007, Gradations in digital inclusions: Children, young people and the digital divide. New media and society vol9 no 4 